$v_{\mathrm{N}} n^{\prime}$ thus corresponds with the angle Y in Prof. Cornu's formula, and its value is derived by precisely the same formula.

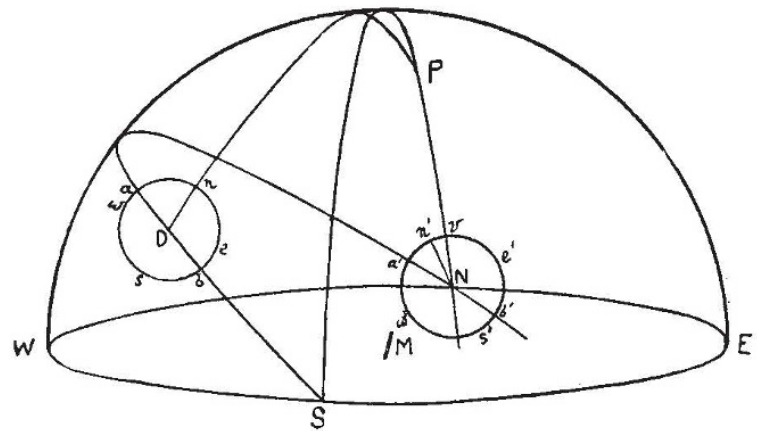

FiG. 3.-Orientation of field of siderostat.

The orientation of the field of a cœlostat is very readily derived. In this instrument the mirror turns on a polar axis in its own plane, so that the normal is always on the equator, and the polar distance of the reflected ray is always equal to the supplement of the polar distance of the star. Thus, in Fig. 4, $\mathrm{PD}^{\prime}$ is the supplement of PD. The reflection of the hour circle through the star, $\mathrm{PD}$, will coincide in direction with that through the reflected ray, $\mathrm{PD}^{\prime}$, so that $n$ will become $n^{\prime}$, and it only remains to determine the angle $\mathrm{PD}^{\prime} \mathrm{z}$ to ascertain the position of the north point with regard to a vertical line through the field of the mirror. If we suppose the rays to be reflected in a horizontal direction, in the triangle $\mathrm{PZD}, \mathrm{PZ}=$ the co-latitude, $\mathrm{ZD}^{\prime}=90^{\circ}$ and $\mathrm{PD}^{\prime}=\mathrm{I} 80^{\circ}-\mathrm{PD}$, so that the required angle can be at once derived. In this case it is convenient to know the azimuth of the reflected ray, that is, $\mathrm{PZD}^{\prime}$ and the simplest solution is to calculate this angle first by the formula

$\cos \mathrm{PZD}^{\prime}=\cos \left(180^{\circ}-\mathrm{PD}\right) \sec \mathrm{L}$.

The requited angle is then derived from the formula

$\sin \mathrm{PD}^{\prime} \mathrm{Z}=\sin \mathrm{PZD}^{\prime} \cos \mathrm{L} \operatorname{cosec}\left(\mathrm{I} 80^{\circ}-\mathrm{PD}\right)$.

The position of the north point having been determined, the remaining points can at once be placed, noting that the east and west points are reversed as compared with the direct view in the sky.

It is important to note that although there is no rotation of the field so long as the telescope remains in one position, the

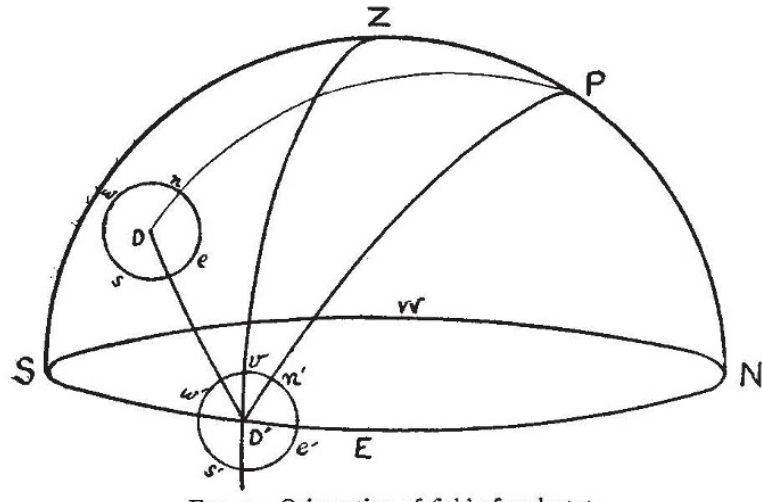

FIG. 4.-Orientation of field of cœlostat.

whole field is turned when the telescope is set in a different jirection. Thus, if the telescope is directed west for observa- tions of the morning sun, the orientation of the field will be different when the telescope is pointed in an easterly direction for observations of the sun in the afternoon; in the former case the north point lies to the right of the vertical, and in the latter case to the left.

Other investigations relating to the cœlostat, including the determination of the best position for the telescope under given conditions; have been made by Prof. H. H. Turner (Monthly Notices R.A.S., vol. lvi. p. 408).

As the coelostat has not yet come into very general use, it may be of interest to add a few remarks as to the arrangements which have been made by Sir Norman Lockyer at the Solar Physics Observatory for utilising this instrument in a permanent observatory (Fig. 5). On account of the varying declinations of the heavenly bodies, the position of the observing telescope must admit of corresponding changes, either in inclination or azimuth, or both. When special instruments, such as the spectro-heliograph, are to be used with the cœelostat, as at the Solar Physics Observatory, motion in azimuth is the only motion permissible, and this is provided for by fixing the receiving instrument on a platform which runs on circular rails, with the cœlostat at the centre. The platform carrying the telescope or spectroscope is covered with a travelling hut, the roof of which

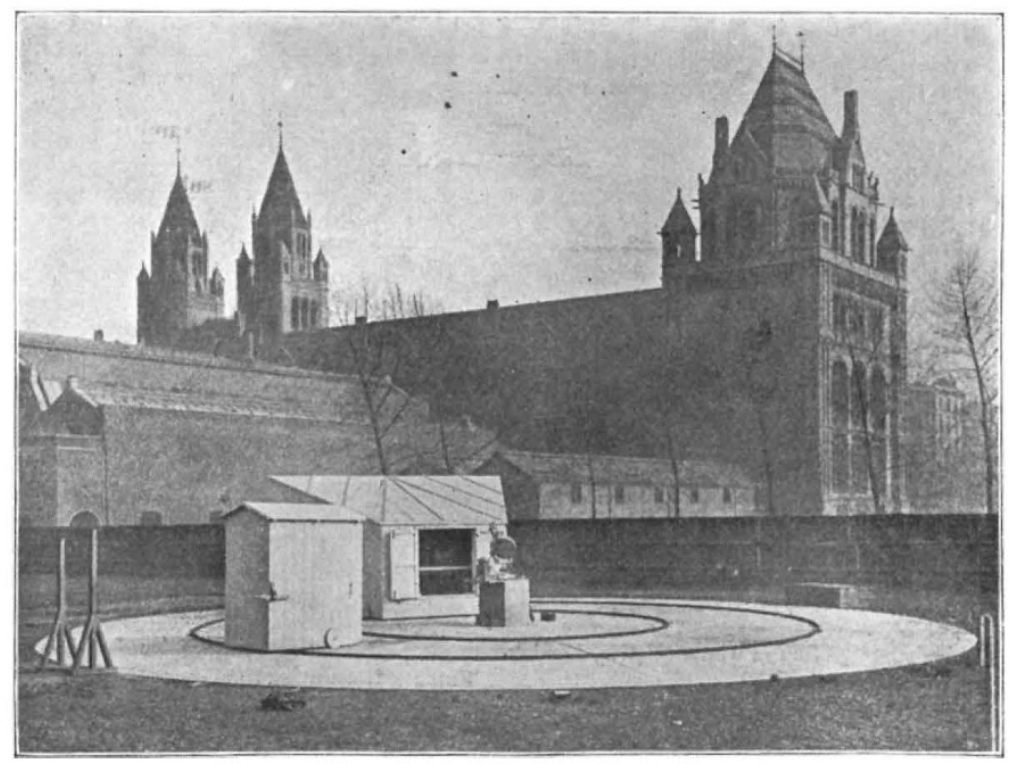

FIG. 5.-The cœlostat of the Solar Physics Observatory.

is inclined so as not to obstruct the mirror. The cœlostat itselt is provided with a hut, which is removed to the north when the instrument is in use ; this is shown to the left in the illustration. A. FOWLER.

\section{THE ANNIVERSARY MEETING OF THE} REALE ACCADEMIA DEI LINCEI.

A MELANCHOLY interest attaches to the anniversary meeting of that ancient scientific society, the Reale Accademia dei Lincei, held in June, from the fact that the society was then mourning the loss of its distinguished president, Prof. Beltrami, and has since been plunged into deeper mourning by the untimely and unexpected loss of its patron, King Humbert, who with Queen Margherita had for many years taken part in these yearly meetings. It is, moreover, largely due to the munificence of the late King of Italy that the society is enabled to further the advancement of science by the award of prizes for theses dealing with some subject of scientific research.

From the presidential report of Prof. Mesadaglia, we learn that the society's losses have included, besides Beltrami, the names of Capasso, De Simoni, Ferrara, Nestore and TommasiCrudeli among the ordinary members, and, of foreign members. Bertrand, Bunsen, Janet and Liais. The Atti, or "Proceedings" contain for the year 147 papers, in addition to which several 
longer papers are being printed in the Memorie or "Transactions," and the corresponding societies with which an exchange of publications is made now number not less than 500. Under the title of Nolizie degli Scavi, the society brings out accounts of archæological discoveries in Italy, the material for which is furnished monthly by the Minister of Public Instruction. Of recent publications, we note the issue of three volumes of the "Codex Atlanticus" of Leonardo da Vinci, a magnificent work, in the cost of publishing which the late King gave material -assistance ; also the "Forma Urbis Romæ" of Signor Lanciani, consisting of a large scale archrological map of Rome.

For the Royal prize of 1000 francs for normal and pathological physiology six candidates entered, and a large number of essays of considerable merit were submitted by them. The prize has been adjudged to Prof. Giulio Fano, of Florence, for sixteen papers, dealing, amongst other subjects, with the physiology of the embryonic heart, the doctrine of experimental psychology, the organ of hearing, the graphic registration of respiratory chimism and reflex movements, the latter being a continuation of previous researches on the organs of Emys Europea. Of the six candidates for the Royal prize for geology and mineralogy, two were considered worthy of the award, which was therefore divided equally between them. One of the successful candidates, Prof. De Lorenzo, chose geological subjects, and sent in about twenty essays, the most important of which dealt with the trias of the environs of Lagonegro, the mesozoic mountains of Lagonegro, geological observations on the Apennines of the southern Basilicate, and geological studies of the southern Apennines. Prof. Giorgio Spezia's work, on the other hand, was entirely mineralogical, dealing with the influences of temperature and pressure, respectively, on the chemical metamorphism of rocks and minerals. From a long and labırious series of experiments, many of them occupying five or six months, the author concluded that pressure has little or no effect, while the influence of temperature is considerable. The results have a special bearing on the theory of quartz formation. The Royal prize for advances in archæulogical science was adjudged to Dr. Paolo Orsi, of Roveredo, for his investigations of the antiquities of Eastern Sicily. Dr. Orsi has thrown quite a new light on the prehistoric development of the people known as the Siculi, from the neolithic epoch down to the period of expansion of the Greek colonies. A special prize for philosophy and moral science had been offered for an essay dealing with either the theory of consciousness or the foundations of practical philosophy. This prize has been divided equally between Prof. Bernardino Varisco and Prof. Francesco de Sarlo. The Minister of Public Instruction offered a sum of 3400 lire for two prizes in physical and chemical sciences, and a like sum for two prizes in philological sciences, the prizes being confined to teachers in secondary schools. The committee for the prizes in physical and chemical sciences have awarded two equal prizes-one to Prof. O. Marco Corbino, more especially for his work on light traversing metallic vapours in a magnetic field, and the other to ke divided between Profs. Carlo Bonacini and Riccardo Malagoli, more especially for their joint papers on Röntgen rays. In philology, the prizes have been divided up into a number of minor awards, distributed between Signori Giuseppe Vandelli (whose work stood first), Antonio Belloni, Astorre Peliegrini, Giuseppe Rua, Giuseppe Lisio, Augusto Balsano, Giovanni Negri and Guglielmo Volpi.

At the conclusion of the awards a biographical commemoration of the late Prof. Beltrami was delivered by Prof. Luigi Cremona. In the number of the Atti, this is followed by a chronological list of Beltrami's scientific works, in compiling which use has been made of the previously published lists by Prof. Dini, and by Signori Pinti and Brambilla in the Annali di Matematica and the Rendiconto of the Naples Academy respectively.

The proceedings terminated with an address by Signor Giuseppe Colombo on the progress of electrotechnics in Italy. Signor Colombo briefly traced the gradual development of the theory of the electrical transmission of energy, from the discovery of Volta, through the various stages indicated by Pacinotti's invention of the first dynamo, Galileo Ferraris' principle of the rotating magnetic field, and a number of intermediate inventions, down to the principle of wireless telegraphy, to the development of which two Italians, Righi and Marconi, have so largely contributed. The absence of coal has long been a serious bar to the progress of Italy in commercial competition, but Signor Colombo proves by statistics that Nature has provided a source NO. 1609, VOL. 62] of energy more than sufficient to fill the deficiency, in the waterpower with which the country has been well endowed, and it only needs the development of plant for the electrical transmission of power, aided, moreover, by the best means for minimising waste of energy, to raise Italy to a condition of commercial prosperity.

\section{UNIVERSITY AND EDUCATIONAL} INTELLIGENCE.

The Pall Mall Gazette states that Miss Cruickshank has given to Aberdeen University, in memory of her brother, Dr. Alexander Cruickshank, the botanic garden at Chanoury, Old Aberdeen, extending to six acres, and capable of accommodating nearly six thousand specimens Miss Cruickshank has devoted to its endowment the sum of $15,000 l$.

Mr. Gilbert R. Redgrave, Senior Chief Inspector in the South Kensington branch of the Buard of Education, has been appointed an Assistant Secretary for Technology. Announcement is made that in the ensuing autumn the Duke of Devonshire will appoint a departmental committee, on which the county councils and the City and Guilds of London Institute will be represented, to consider, inter alia, the co-ordination of the technological administration of the Board of Education with the technological work at present carried on by educational bodies other than that Board.

A GOOD idea of the scope and value of the work of the examinations department of the City and Guilds of London Institute can be obtained from the "Programme of Technological Exaninations (1900-190I)," published by Messrs. Whittaker and Co. Examinations are held in seventy technological subjects, and also in manual training (wood-work and metalwork). For each examination a syllabus is given, and a useful list of works of references; and the questions and practical exercises set at the recent examinations are all reprinted. Several of the syllabuses have been revised, notably those of photography, pottery and porcelain, silk throwing and spinning, and silk weaving, electric lighting, watch and clock making, typography, lithography, carpentry and joinery.

THE Redruth School of Mines, of which the syllabus for 1900-190I is before us, offers exceptional facilities for study. ing the principles of mining in the Cornish mining district. One wing of the school building is occupied by a large mineral gallery, erected to the memory of the late Dr. Robert Hunt, F.R.S. The museum, which contains a valuable collection of mineral specimens, and is the property of the Mining Association and Institute of Cornwall, is at all times accessible to students of the school. The mining course consists of practical underground work, including the timbering of shafts and leveis, and of lectures on geology, the principles of mining, the raising and mechanical preparation of ores, and of practical work in gold panning and vanning. Students, in addition, are taught the methods of prospecting for minerals in all possible positions, and are trained to detect favourable indications on the surface. There is thus a reasonable combination of science with practice in subjects essential to the training of mining engineers.

WhAT school gardens are to children, allotments are to adults in agricultural districts, and both provide valuable means of experiment. The Report of the Technical Instruction Committee of the Oxfordshire County Council shows that this is well recognised is several parts of the county. For instance, at the Chipping Norton Agricultural Class there were fifty-four students of an average age of thirty-eight. They were factory hands, labourers, mechanics and small tradesmen, who all cultivated allotments, and were thus able to put principles to a practical test, and determine the causes thus affecting growth. At Reading College, which is connected with the Uxfordshire Committee, various insects and plants were received from different parts of the county for identification, and advice was given in many localities. Field experiments were made on sainfoin and lucerne, rotation, "finger and toe," mangel, and different manures for barley. Charlock spraying was investigated at three farms, and other experimental work had been done under the auspices of the College and the Technical Education Committee. 